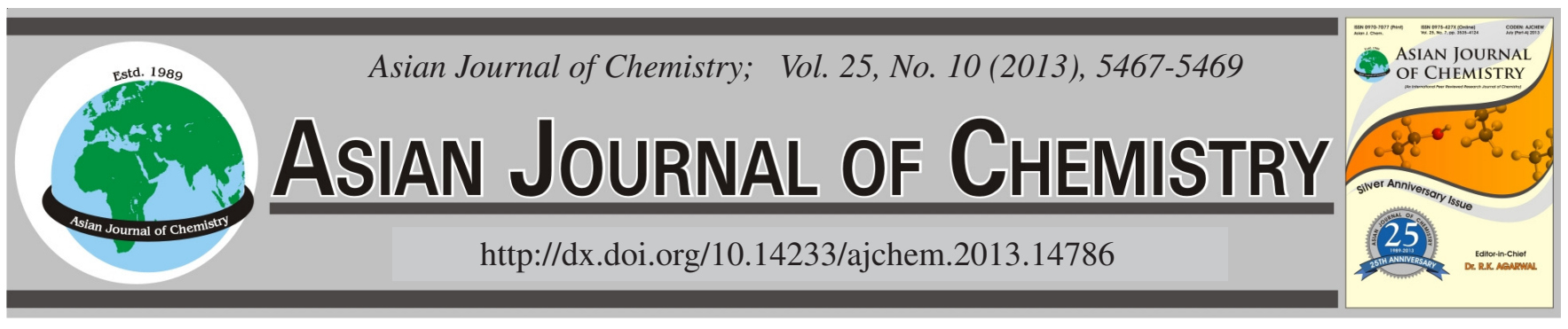

\title{
Investigation of Langmuir, Freundlich and Temkin Adsorption Isotherm of Tramadol by Multi-Wall Carbon Nanotube
}

\author{
Mehdi Vadi ${ }^{1, *}$, Asma Omidi Mansoorabad ${ }^{2}$, Majid Mohammadi $^{2}$ and Nasrin Rostami ${ }^{2}$
}

${ }^{1}$ Department of Chemistry, Fasa Branch, Islamic Azad University, Fasa, Fars, Iran

${ }^{2}$ Department of Chemistry, Gachsaran Branch, Islamic Azad University of Gachsaran, Kohgiloyeh va Boyerahmad, Iran

*Corresponding author: E-mail: mahdi_vadi@iaufasa.ac.ir

(Received: 5 November 2012;

Accepted: 13 April 2013)

AJC-13231

\begin{abstract}
In this experimental research the adsorption of the isotherm of tramadolas, a kind of narcotic drugs is studied on the multi-wall carbon nanotube with the spectrophotometer. The amount of adsorption in various concentrations was calculated and its related diagram was drawn. The result, which was obtained by Langmuir, Freundlich and Temkin in $296 \pm 2 \mathrm{~K}$, compared coefficient parameters show that the Temkin has the most accordance.
\end{abstract}

Key Words: Adsorption, Isotherm, Tramadol, Narcotic drugs, Multi-wall carbon nanotube.

\section{INTRODUCTION}

Carbon nanotubes having nano scale dimension (1-D) have been well-known over the past 15 years. The molecules were first discovered by Iijima in $1991^{1}$ when studying the synthesis of fullerenes by using electric arc discharge technique. The high resolution transmission electron microscopy (HRTEM) was employed for observation of that phenomenon. Carbon nanotubes that Iijima observed were so called multiwalled carbon nanotubes (MWCNTs), nested as Russian dolls, containing at least two graphitic layers and generally have inner diameters of around $4 \mathrm{~nm}$. Two years later, Iijima and Ichihashi ${ }^{2}$ and Bethune and colleagues ${ }^{3}$ reported the applications of single walled carbon nanotubes. The SWCNTs were synthesized by the same route of producing MWCNTs but adding some metal particles to the carbon electrodes. The appearance of SWCNT is quite different to that of MWCNT. The individual tubes have very small diameters (typically ca. $1 \mathrm{~nm}$ ) and are curled and looped rather than straight. In the early 1990s, two research groups predicted electronic properties of individual SWCNTs ${ }^{4-6}$. From their calculations, they found that SWCNTs can be either metallic or semiconducting depending on their chirality and diameter. By the end of that decade, these particular predictions were confirmed by experiments ${ }^{7,8}$. In the meantime, a lot of reviews which provide a comprehensive overview with respect to the synthesis, characterization, applications and the basic mechanical and electronic properties of carbon nanotube have appeared $^{9-22}$. Because of many interesting properties that carbon nanotubes exhibit, CNTs have emerged to be one of the most intensively investigated nanostructure materials. The word analgesic derives from Greek an- ("without") and algos ("pain").Analgesic drugs act in various ways on the peripheral and central nervous systems; they include paracetamol ( $p$ acetylaminophenol, also known in the US as acetaminophen), the non steroidalantiinflammatory drugs (NSAIDs) such as the salicylates and opioid drugs such as morphine and opium. They are distinct from anesthetics, which reversibly eliminate sensation In choosing analgesics, the severity and response to other medication determines the choice of agent, the WHO pain ladder, originally developed in cancer related pain, is widely applied to find suitable drugs in a stepwise manner ${ }^{23}$. The analgesic choice is also determined by the type of pain e.g., for neuropathic pain, traditional analgesics are less effective and there is often benefit from classes of drugs that are not normally considered analgesics, such as tricyclic antidepressants and anticonvulsants ${ }^{24}$. The inflammation response of our bodies is a key part of the healing process. Using NSAIDs to reduce the inflammation has been shown to impair healing in different tissue types e.g., muscles ${ }^{25}$.

Tramadol hydrochloride (trademarked as Conzip, Ryzolt, Ultracet, Ultram in the USA, Ralivia and Zytram XL in Canada) is a centrally-acting synthetic analgesic used to treat moderate to moderately-severe pain ${ }^{26,27}$. Designated chemically as (1R,2R)-rel-2-[(dimethylamino)methyl]-1-(3-methoxyphenyl) cyclohexanol. The molecular weight is $263.4 \mathrm{~g} / \mathrm{mol}$. Its molecular formula is $\mathrm{C}_{16} \mathrm{H}_{25} \mathrm{NO}_{2}$ and the structural formula is: 
<smiles>COc1cccc(C2(O)CCCC[C@H]2CN(C)C)c1</smiles><smiles>COc1cccc(C2(O)CCCC[C@H]2CN(C)C)c1</smiles>

\section{EXPERIMENTAL}

We used the carbon nanotube with $95 \%$ pure degree, production of Neutrino Company. We used the tramadol production of Aborihan Company of Iran.

In this survey the spectrophotometer (Jenway6505, Model, England), magnetic stirrer (Heidolph, Mr3001 Model), Analytical balances (Sartorius Model), Filter paper (Albet), were used.

Method: At first we solved $0.01 \mathrm{~g}$ of tramadol in $100 \mathrm{~mL}$ of water and make (100 ppm) solution. After dilution of this solution the consistencies (5-7-9-11) ppm were produced. 10 $\mathrm{mL}$ of each concentration was taken and $0.01 \mathrm{~g}$ of multi-walled carbon nanotube (MWCNT) was added to each part. This solution was mixed about 10 min with magnetic stirrer. Then amount of concentration was measured with spectrophotometer before and after adding carbon nanotube.

\section{RESULTS AND DISCUSSION}

Study of adsorption isotherms: At first we used this relation ${ }^{28}$ for assessing the adsorption capacity:

$$
\mathrm{q}_{\mathrm{e}}=\frac{\left(\mathrm{C}_{0}-\mathrm{C}_{\mathrm{e}}\right) \mathrm{v}}{\mathrm{M}}
$$

In this equation $\mathrm{C}_{0}$ and $\mathrm{C}_{\mathrm{e}}$ are related to the primary concentration and final concentratio of tramadol solution $(\mathrm{mg} /$ $\mathrm{L}$ ) and $\mathrm{V}$ is volume solution ( $\mathrm{L}$ ) and $\mathrm{M}$ is mass of adsorbate (g).

Langmuir adsorption model: This model used for monolayer adsorptions. This model formed by the supposition of the equality of energy in the of all the adsorb sites on this adsorbent surface. This model is described in this equation which is its linear form ${ }^{29}$.

$$
\frac{1}{q_{e}} \frac{1}{\left(k_{a} c_{e}\right)} \frac{1}{q_{m}}
$$

Here $\mathrm{q}_{\mathrm{e}}$ and $\mathrm{c}_{\mathrm{e}}$ are the amount of adsorption dissolve at equilibrium $\left(\mathrm{mg} \mathrm{g}^{-1}\right)$ and the equilibrium concentration $\left(\mathrm{mg}^{-1}\right)$, respectively. Langmuir constants, $\mathrm{k}_{\mathrm{a}}\left(\mathrm{mg} \mathrm{L}^{-1}\right)$ and $\mathrm{q}_{\mathrm{m}}\left(\mathrm{mg} \mathrm{g}^{-1}\right)$ are related to the energy of adsorption and the adsorption capacity, respectively. One of the characteristic of the Langmuir equation is dimensionless of detachment coefficient $\mathrm{R}_{\mathrm{L}}{ }^{30}$ can be gained from (3) relationship.

$$
\mathrm{R}_{\mathrm{L}}=\frac{1}{\mathrm{k}_{\mathrm{a}} \mathrm{c}_{0}}
$$

By regarding adsorption with the help of spectrophotometer and the above relation, adsorption Langmuir graph to the $1 / \mathrm{q}_{\mathrm{e}}$ against $1 / \mathrm{C}_{\mathrm{e}}$ is plotted (Fig. 1) and its calculated parameters can be seen in Table-1.

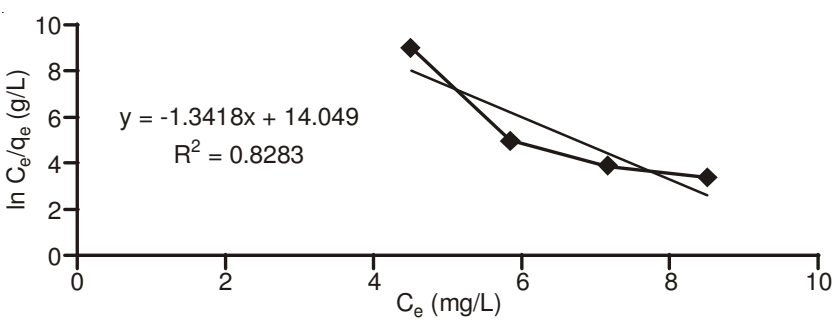

Fig. 1. Adsorption equilibrium of tramadol based Langmuir isotherm

Temkin model: Temkin isotherm has one factor which shown the interaction between adsorbent and adsorbing particle so vividly. This model was applied in forms, given as eqn. 4 bellow:

$$
\begin{gathered}
\mathrm{q}_{\mathrm{e}}=\mathrm{B} \ln \mathrm{A}+\mathrm{B} \ln \mathrm{c}_{\mathrm{e}} \\
\mathrm{B}=\frac{\mathrm{RT}}{\mathrm{b}}
\end{gathered}
$$

By plotting $\mathrm{q}_{\mathrm{e}}$ against lnce gave the constants, $\mathrm{A}$ and $\mathrm{B}$ which are the Temkin isotherm constants $(\mathrm{L} / \mathrm{mg})^{31}$ and the Temkin constant related to heat of adsorption $\left(\mathrm{J} \mathrm{mol}^{-1}\right)$, respectively is the gas constant $(8.314 \mathrm{~mol} / \mathrm{k}) \mathrm{B}$ is also a Temkin isotherm constant while is the absolute temperature in Kelvin. By regarding adsorption with the help of spectrophotometer and the above relation, adsorption Temkin graph to the $\mathrm{q}_{\mathrm{e}}$ against $\ln c_{\mathrm{e}}$ is plotted (Fig. 2) and its calculated parameters canbe seen in Table-1.

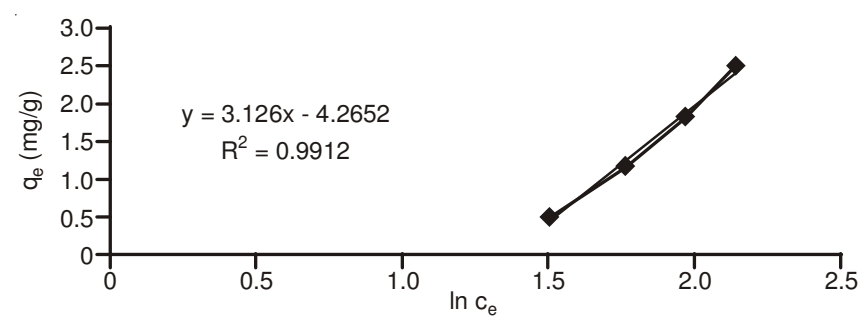

Fig. 2. Adsorption equilibrium of tramadol based Temkin isotherm

Freundlich model: It is an experimental equation which in used more in adsorption metallic ions on heterogeneous surface with the multilayer adsorption. The amount of dissolved solvent will increase infinitely with increase of concentration. The linear Freundlich model is expressed as shown in eqn. 3 ;

$$
\ln \mathrm{q}_{\mathrm{e}}=\ln \mathrm{k}_{\mathrm{f}} \pm \ln \mathrm{c}_{\mathrm{e}}
$$

$\mathrm{q}_{\mathrm{e}}$ and $\mathrm{c}_{\mathrm{e}}$ is the amount of dissolve adsorption at equilibrium $(\mathrm{mg} / \mathrm{g})$ and equilibrium concentration $(\mathrm{mg} / \mathrm{L})$, respectively. $\mathrm{k}_{\mathrm{f}}$ and are factor which affect the adsorption process (adsorption capacity and intensity, respectively).

\begin{tabular}{ccccccccc}
\hline & Langmuir & \multicolumn{3}{c}{ Freundlich } & \multicolumn{3}{c}{ Temkin } \\
\hline $\mathrm{b}$ & $\mathrm{q}$ & $\mathrm{R}^{2}$ & $\mathrm{n}$ & $\mathrm{K}\left(\mathrm{L} \mathrm{g}^{-1}\right)$ & $\mathrm{R}^{2}$ & ${\mathrm{~A}\left(\mathrm{~L} \mathrm{mg}^{-1}\right)}$ & $\mathrm{B}$ & $\mathrm{R}^{2}$ \\
\hline 1.016 & 100 & 0.82 & 1.03 & 1.57 & 0.98 & 0.99 & 4.37 & 0.99 \\
\hline
\end{tabular}


By regarding adsorption ${ }^{32}$ with the help of spectrophotometer and the above relation, adsorption Freundlich graph to the $\ln c_{\mathrm{e}}$ against $\ln \mathrm{q}_{\mathrm{e}}$ is plotted (Fig. 3) and its calculated parameters can be seen in Table- 1 .

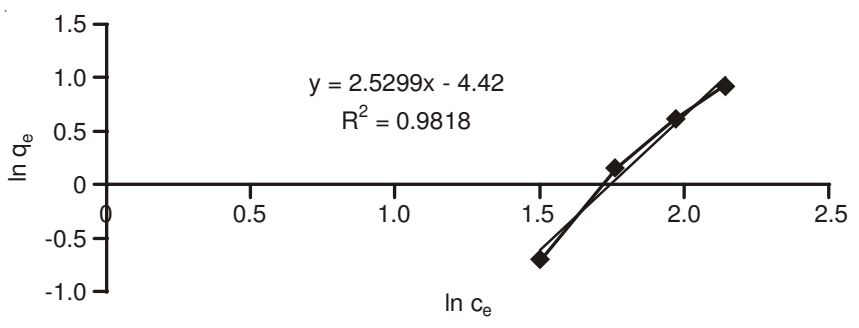

Fig. 3. Adsorption equilibrium of tramadol based Freundlich isotherm

The result of isotherms (Table-1) show the value range obtained for the Temkin model is high compared to those of both the Freunlich and Langmuir models. It therefore stands for this adsorption studies, the Temkin model is most suitable and that applicability follows the order; Temkin $>$ Freundlich $>$ Langmuir adsorption model. If in Langmuir isotherm ${ }^{33}, \mathrm{R}_{\mathrm{L}}$ $>1$ then the kind of Langmuir model is undesirable for the experiment. For $\mathrm{R}_{\mathrm{L}}=1$ there exist a line process and if $1>\mathrm{R}_{\mathrm{L}}$ $>0$, the process is desirable. If $R_{L}=0$ then the isotherm is irreversible.

\section{Conclusion}

The results of this survey show the correlation coefficient of Temkin isotherm equation has the best accordance and its adsorption energy is high. The result of parameters show the suitable efficiency of multi-wall carbon nanotube in adsorption of tramadol. However, multi-wall carbon nanotube, has the ability to intake the narcotic drugs in alive creatures and or with narcotic drugs adsorption by multi-wall carbon nanotube and directs the drugs to the interested cells.

\section{REFERENCES}

1. S. Iijima, Nature, 354, 56 (1991).

2. S. Iijima and T. Ichihashi, Nature, 363, 603 (1993).

3. D.S. Bethune, C.H. Kiang, M.S. De Vries, G. Gorman, R. Savoy, J. Vazquez and R. Beyers, Nature, 363, 605 (1993).

4. N. Hamada, S. Sawada and A. Oshiyama, Phys. Rev. Lett., 68, 1579 (1992).

5. R. Saito, M. Fujita, G. Dresselhaus and M.S. Dresselhaus, Phys. Rev. B, 46, 1804 (1992)
6. R. Saito, M. Fujita, G. Dresselhaus and M.S. Dresselhaus, Appl. Phys. Lett., 60, 2204 (1992).

7. J.W.G. Wildoer, L.C. Venema, A.G. Rinzler, R.E. Smalley and C. Dekker, Nature, 391, 59 (1998).

8. T.W. Odom, J.L. Huang, P. Kim and C.M. Lieber, Nature, 391, 62 (1998).

9. M. Burghard, Surf. Sci. Rep., 58, 1 (2005).

10. S.B. Sinnott and R. Andrews, Crit. Rev. Solid State Mater. Sci., 26, 145 (2001).

11. C.N.R. Rao, B.C. Satishkumar,A. Govindaraj and M. Nath, ChemPhys Chem, 2, 78 (2001).

12. P. Avouris, Acc. Chem. Res., 35, 1026 (2002).

13. J. Bernholc, D. Brenner, M.B. Nardelli, V. Meunier and C. Roland, Ann. Rev. Mater. Res., 32, 347 (2002).

14. T. Ando, J. Phys. Soc. (Japan), 66, 1066 (1997).

15. H.J. Dai, Surf. Sci., 500, 218 (2002).

16. M. Terrones, Ann. Rev. Mater. Res., 33, 419 (2003).

17. S. Reich, C. Thomsen and J. Maultzsch, Carbon Nanotubes: Basic Concepts and Physical Properties, Wiley-VCH, Weinheim (2004).

18. V.N. Popov, Mater. Sci. Eng. R. Rep., 43, 61 (2004).

19. M.S. Dresselhaus, G. Dresselhaus and A. Jorio, Ann. Rev. Mater. Res., 34, 247 (2004).

20. M. Meyyappan, Carbon Nanotubes-Science and Applications, CRC Press Boca Raton (2004).

21. M. Daener, R.D. De Fouw, B. Hamers, P.G.A. Janssen, K. Schouteden and M.A.J. Veld, The Wondrous World of Carbon Nanotubes, Eindhoven University of Technology (2003).

22. D. Zhang and C.L. Lin, Carbon Nanotube Final Report (2003).

23. Anonymous Cancer Pain Relief and Palliative Care; Report of a WHO Expert Committee, World Health Organization Technical Report Series, 804. Geneva, Switzerland: World Health Organization, pp. 1-75 (1990).

24. R.H. Dworkin, M. Backonja, M.C. Rowbotham, R.R. Allen, C.R. Argoff, G.J. Bennett, M.C. Bushnell, J.T. Farrar, B.S. Galer, J.A. Haythornthwaite, D.J. Hewitt, J.D. Loeser, M.B. Max, M. Saltarelli, K.E. Schmader, C. Stein, D. Thompson, D.C. Turk, M.S. Wallace, L.R. Watkins and S.M. Weinstein, Arch. Neurol., 60, 1524 (2003).

25. T.A. Trappe, J.D. Fluckey, F. White, C.P. Lambert and W.J. Evans, J. Clin. Endocrinol. Metab., 86, 5067 (2001).

26. R.M. Julien, In eds.: C.D. Advokat and J.E. Comaty, A Primer of Drug Action, New York: Worth Publishers, edn. 11, p. 537 (2008).

27. M.P. Mangione and M. Matoka, J. Gen. Intern. Med., 23, 1336 (2008).

28. R.H. Baughman, A.A. Zakhidov and W.A. De Heer, Science, 297, 787 (2002).

29. H.L. Mudoga, H. Yucel and N.S. Kincal, Bioresour. Technol., 99, 3528 (2009).

30. F. Abdurrahman, L. Hassan, U. Itodo and S. Maigandi, Nigeria J. Basic Appl. Sci., 16, 256 (2008).

31. A. Zahangir, A. Suleyman and K. Noraini, Production of Activated Carbon from Oil Palmempty Fruit Bunch for Zn Removal, Conference Proceedings 12th Int Water Tech Conf. IWTC12 Egypt: pp. 373-383 (2008)

32. M. Jain, V.K. Garg and K. Kadirvelu, J. Hazard. Mater., 162, 365 (2009).

33. B.H. Hameed, A.T.M. Din and A.L. Ahmad, J. Hazard. Mater., 141, 819 (2007). 